\title{
Analysis of Power and Dimensions of European Tractors
}

\author{
J. Karner \\ Josephinum Research, Wieselburg, \\ Austria
}

\begin{abstract}
The tractor is an important machine for every European farmer. It is typically propelled by a Diesel-engine, while pure electric and hybrid drives gain interest. Only a few international manufacturers are manufacturing the enormous scope of tractor-models available on the European market. To save costs, several platform models have been established. They are labelled and sold under various brands. Therefore, 117 tractor models have been analyzed that were available on the Austrian market until the end of 2013. The aim was to identify if there are correlations of technical data (e.g. power and vehicle mass). Some additional values have been derived from them. It could be shown, that large tractors are equipped with relatively small sized tires. Large tractors generate higher pressure and shear stress in the contact area than small ones. A factor for the tire diameter was developed to obtain equal pressure and shear stress.
\end{abstract}

Keywords agricultural tractors; power; tire; dimensions

\section{INTRODUCTION}

A tractor is an important machine for every European farmer that is used to accomplish a wide variety of applications and implements. Low production- and operation-costs are essential for its user, as well as for the manufacturer to be successful on the market. Consequently, tractor-manufacturers are developing tractor-platform models [1]. The diverse global requirements refer to different engine power, gearbox, PTO speeds, IT-levels, and exhaust-gas systems [2]. The power of new tractor models increases steadily, as does their mass. Therefore, it is interesting to compare data from tractors of different sizes.

\section{MATERIAL AND METHOD}

Relevant data of tractors which were available on the Austrian market until the end of 2013 (Table I) have been collected by RAMMEL [3] at the Francisco Josephinum in Wieselburg (Austria). The analyzed tractors represent about $88 \%$ of the newly registered tractors in Austria in 2013 [4]. The data have been collected from online databases and brochures. Own measurements have not been executed. The power values considered different test codes [5, 6]. Furthermore, relevant values have been calculated from the collected data:

$$
\begin{gathered}
c_{m}=\frac{H \cdot n}{30} \\
P_{l t}=\frac{P_{n o m}}{V_{H}}
\end{gathered}
$$

$$
\begin{gathered}
G_{P}=\frac{G}{P_{\text {nom }}} \\
p_{i}=\frac{120 \cdot P_{\text {nom }}}{V_{H} \cdot n}
\end{gathered}
$$

Herein the mean piston velocity is $c_{m}$ (in $\mathrm{m} / \mathrm{s}$ ), the piston stroke $\mathrm{H}$ (in $\mathrm{m}$ ), the rated engine speed $\mathrm{n}$ (in $\mathrm{rpm}$ ), the relative engine power $\mathrm{P}_{\mathrm{lt}}$ (in $\mathrm{kW} / \mathrm{cm}^{3}$ ), the nominal engine power $\mathrm{P}_{\text {nom }}$ (in $\mathrm{kW}$ ), the displacement $\mathrm{V}_{\mathrm{H}}\left(\right.$ in $\mathrm{cm}^{3}$ ), the weight per power $\mathrm{G}_{P}$

\begin{tabular}{|c|c|}
\hline Brand & Model type \\
\hline Fendt & $\begin{array}{c}\text { 207, 209, } 211 \text { Vario; } 309,311,313 \text { Vario; } 411,413,415 \\
\text { Vario; 512, 514, 516 Vario; 716, 720, } 724 \text { Vario; } 822, \\
826,828 \text { Vario; } 927,933,939 \text { Vario }\end{array}$ \\
\hline Claas & $\begin{array}{c}\text { 210, 230, Elios; } 310,340 \text { Axos; 410, } 430 \text { Arion; 530, } 550 \\
\text { Arion; } 620,650 \text { Arion }\end{array}$ \\
\hline $\begin{array}{l}\text { John } \\
\text { Deere }\end{array}$ & $\begin{array}{c}\text { 5080, } 5090 \mathrm{G} ; 5070,5100 \mathrm{M} ; 5080,5100 \mathrm{R} ; 6115,6140 \\
6170 \mathrm{M} ; \\
6105,6150,6210 \mathrm{R} ; 7200,7230,7280 \mathrm{R} ; 8260,8310 \\
8360 \mathrm{R}\end{array}$ \\
\hline Lindner & $\begin{array}{c}\text { 64, 74, 84ep, 94 Geotrac; } \\
104,114 \mathrm{ep}, 124,134 \mathrm{ep} \mathrm{Geotrac}\end{array}$ \\
\hline Steyr & $\begin{array}{l}4055 \text { Kompakt S; 4085, } 4105 \text { Kompakt; 4095, } 4115 \\
\text { Multi; } \\
\text { 4130, } 6140 \text { Profi; } 4130 \text { Profi-CVT; 6130, 6185, } 6230 \\
\text { CVT }\end{array}$ \\
\hline Case & $\begin{array}{c}\text { 55 C, } 75 \text { C Farmall; 110, 130, 140 Maxxum; } \\
\text { 130, 185, } 230 \text { Puma CVX; 235, 290, } 340 \text { Magnum }\end{array}$ \\
\hline Valtra & $\begin{array}{c}83,93 \mathrm{~A} ; 113,143,163 \mathrm{~N} ; 132,172,202 \mathrm{~T} \text { Versu; } 232 \\
292,352 \mathrm{~S}\end{array}$ \\
\hline $\begin{array}{l}\text { Deutz- } \\
\text { Fahr }\end{array}$ & $\begin{array}{l}\text { 310, } 320 \text { Agroplus; 410, } 420 \text { Agroplus; } 5100,5110,5120, \\
5130 \text { TTV; } \\
\text { 6150.4, 6160, } 6190 \text { TTV; 7210, 7230, } 7250 \text { TTV }\end{array}$ \\
\hline $\begin{array}{l}\text { Massey- } \\
\text { Ferguson }\end{array}$ & $\begin{array}{c}3660 \mathrm{~F} ; 5608,5610 \mathrm{MF} ; 6612,6615 \text { Dyna-4; } \\
\text { 6614, 6616 Dyna-6; 7614, 7619, } 7626 \mathrm{MF}\end{array}$ \\
\hline
\end{tabular}
(in $\mathrm{kg} / \mathrm{kW}$ ), the weight $\mathrm{G}$ (in $\mathrm{kg}$ ), and the mean piston pressure $\mathrm{p}_{\mathrm{i}}$ (in $\mathrm{Pa}$ ).

TABLE I. ANALYZED TRACTOR MODELS

\section{RESULTS \& DISCUSSION}

\section{A. Power related data}

The power primarily describes the size or strength of a tractor. Its value can be calculated from the measured torque and speed. The rated speed is typically between 2.000 and $2.300 \mathrm{rpm}$. The values of displacement are shown in Figure 1. 


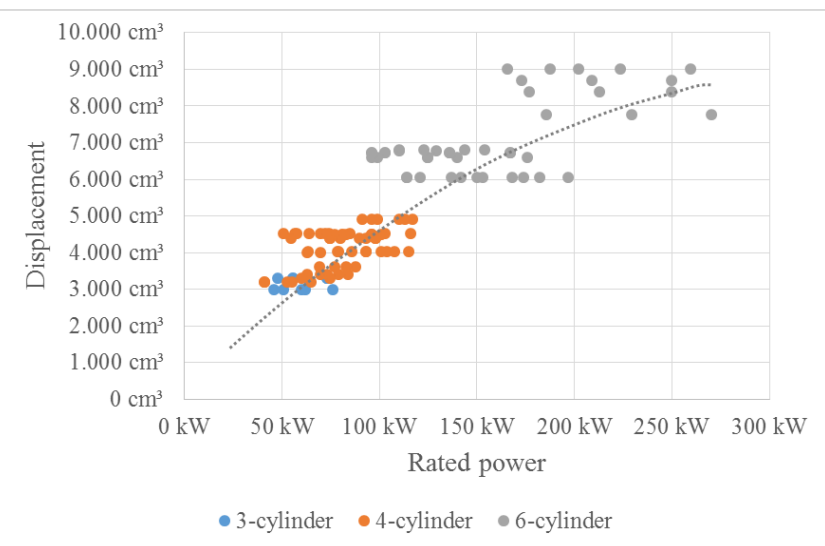

Figure 1. Displacement with respect to engine-power and number of cylinders

Three-cylinder engines, as well as four-cylinder engines, are used up to about $75 \mathrm{~kW}$ nominal power. The latter extend up to $120 \mathrm{~kW}$, some already beyond. This power value was subject to six-cylinder engines some years ago. Nowadays six cylinders can be divided into two classes. On the one hand the class with six to seven liters of displacement and characteristic power between $100 \mathrm{~kW}$ and $200 \mathrm{~kW}$. On the other hand, the class up to nine liters releases $165 \mathrm{~kW}$ to $270 \mathrm{~kW}$. It is obvious that there is no linear correlation between displacement and power, but a degressive one over the whole range. It can be concluded, that the strongest tractors within one class release their power from increased piston pressure rather than power out of pure displacement.

In a simple manner, the number of cylinders could be increased for more power. However, this would be accompanied by additional material and manufacturing costs.

The friction caused by the piston velocity restricts the rated engine speed. Typical values for tractors are between 8.80 and $10 \mathrm{~m} / \mathrm{s}$.

Based on available data of rated power, engine speed and displacement it is possible to derive the mean piston pressure. An increase of the piston pressure will raise mechanical and thermal stress of the engine components (crankshaft, connecting rods, valves). Typical values are between 10 and 15 bar (see Figure 2).

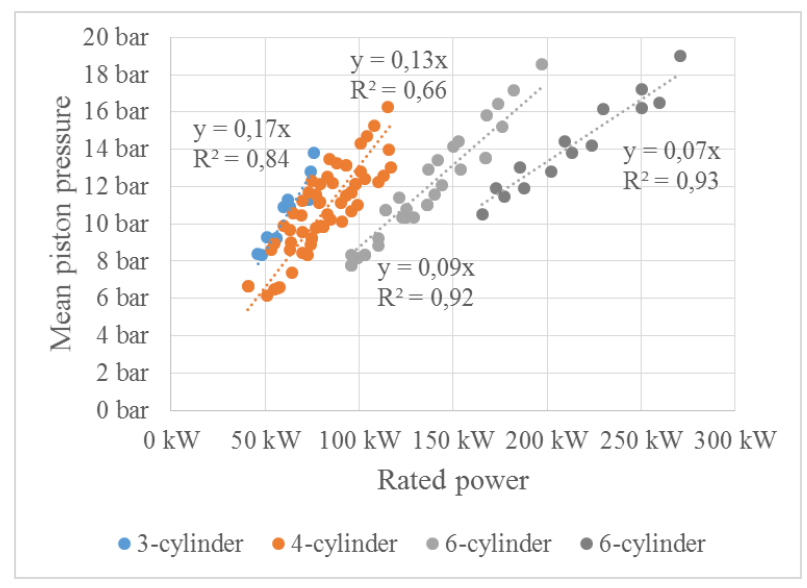

Figure 2. Calculated mean piston pressure of the analyzed tractors

The most powerful models of a certain type of tractor are often significantly higher. The peak values reach to about 20 bar, while small tractor engines have just under 10 bar of mean piston pressure on average.
The engine output per liter displacement indicates a wide range (from 40 to $80 \mathrm{~kW} / \mathrm{dm}^{3}$ ). Therefrom different stress levels can be concluded.

If the tractor weight is related to the nominal power, then a linear regression can be obtained up to about $140 \mathrm{~kW}$ (Figure 3). Beyond that, the data-variance increases. Among all analyzed tractors, the tractor mass would statistically increase by $45 \mathrm{~kg}$ per $\mathrm{kW}\left(\mathrm{R}^{2}=0.88\right)$, when using a linear regression model. The highest value $\left(\mathrm{R}^{2}=0.90\right)$ over the whole range is obtained using a power series regression model.

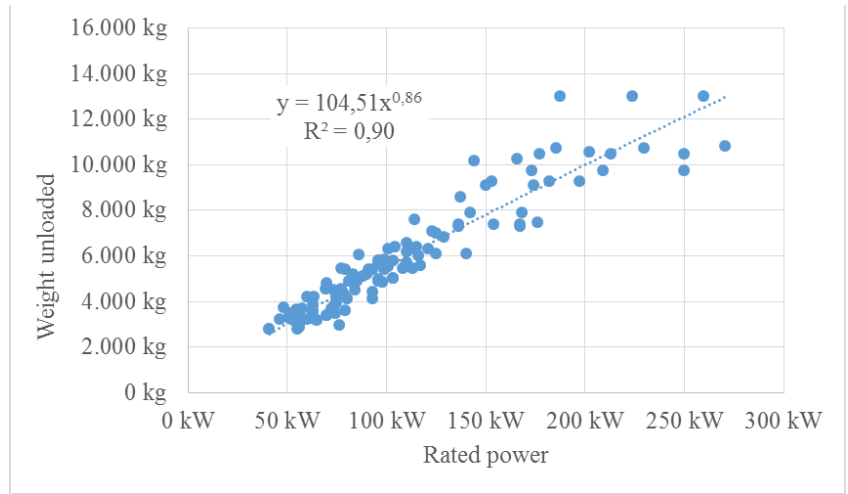

Figure 3. Unloaded weight with respect to rated power

\section{B. Wheelbase and Dimensions}

The tractor's wheelbase was selected as a dimension of the tractor size. Figure 4 shows the nominal power as a function of the wheelbase.

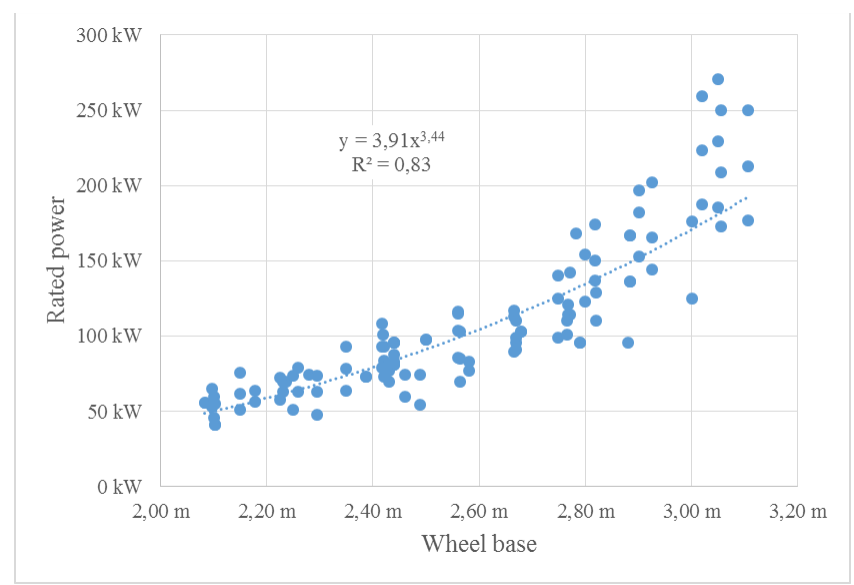

Figure 4. Rated power as function of the wheelbase

The wheelbase of a $90 \mathrm{~kW}$ tractor is about $2.50 \mathrm{~m}$ on average, that of a $150 \mathrm{~kW}$ tractor already $2.85 \mathrm{~m}$. Interestingly enough, the power increases disproportionately with the wheelbase. The calculated power function delivers an exponent of $3.44\left(\mathrm{R}^{2}=0.83\right)$.

Similar figures can be obtained with the unloaded weight referred to the wheelbase (Figure 5).

The regression`s exponent here is $3.23\left(\mathrm{R}^{2}=0.89\right)$. 


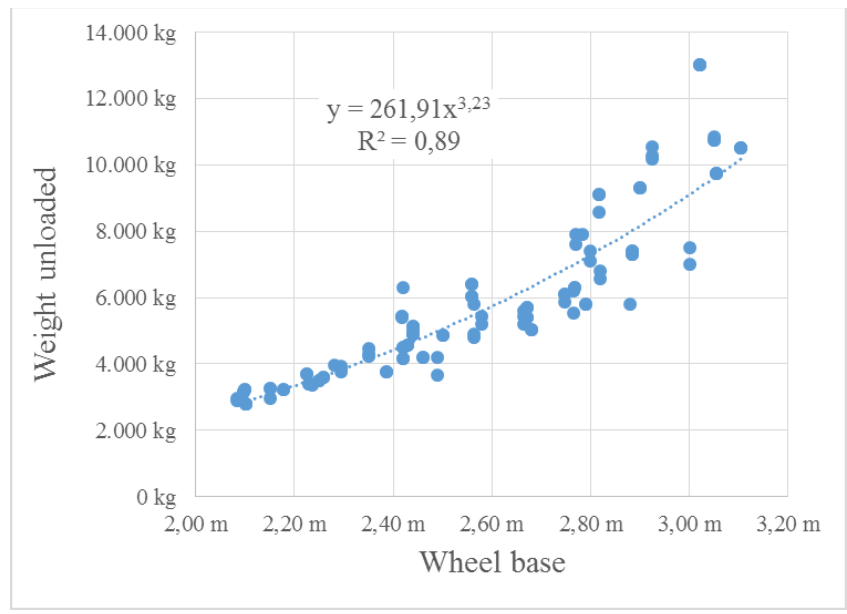

Figure 5. Tractor mass increases with $3^{\text {rd }}$ exponent of the wheel base

Apparently, the tractor mass follows the physical principles of a simple homogenous block: The mass follows the cube of the wheelbase. Similar results can be found in [8].

But the standard tire diameter increases just linearly with the wheelbase of tractors (Figure 6).

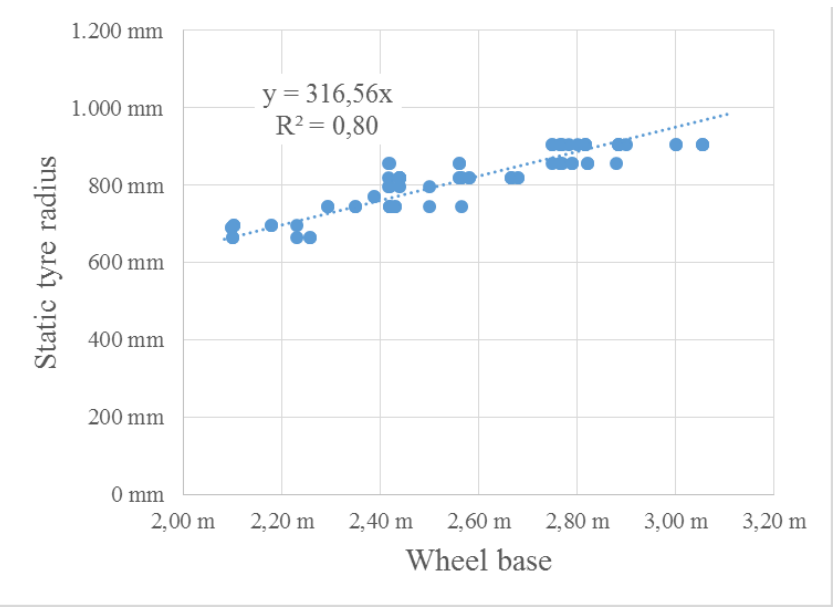

Figure 6. Diameter of the rear tires as function of the wheelbase

\section{Constant pressure in contact surface}

The tire diameter increases as well as the tire width. If we consider, that the contact surface is a square function of the tire diameter, the contact pressure will increase with the tractor size. The pressure $\mathrm{p}_{0}$ of a reference tractor is:

$$
p_{0} \approx \frac{m_{0}}{A_{R, 0}}
$$

The variable $m_{0}$ is the unloaded weight of the reference tractor, $A_{R, 0}$ the contact surface area.

If we consider the enlargement of a tractor in its dimensions by a factor $\lambda$, then consequently the contact pressure $\mathrm{p}_{1}$ is also higher than $\mathrm{p}_{0}$ :

$$
p_{1} \approx \frac{m_{0} \cdot \lambda^{3,23}}{A_{R, 0} \cdot \lambda^{2}}>\frac{m_{0}}{A_{R, 0}} \approx p_{0}
$$

For equal contact pressure underneath the wheels $\left(\mathrm{p}_{1}=\mathrm{p}_{0}\right)$ the tire diameter should increase more than the entire tractor dimensions (represented by the wheelbase). The tire enlargement is described by the factor $\varphi$.

$$
p_{1} \approx \frac{m_{1}}{A_{R, 1}}=\frac{m_{0} \cdot \lambda^{3,23}}{A_{R, 0} \cdot(\lambda \cdot \varphi)^{2}}=\frac{m_{0}}{A_{R, 0}}
$$

The factor $\varphi$ can be calculated as follows:

$$
\begin{gathered}
\lambda^{3,23}=\lambda^{2} \cdot \varphi^{2} \\
\varphi=\sqrt{\lambda^{1,23}}
\end{gathered}
$$

Equal contact pressure requires an enlargement factor of $\varphi=\sqrt{\lambda^{1,23}}$ additionally to the proportional scaling (factor $\lambda$ ) in dimensions. The tire diameter should be enlarged more than the wheelbase.

Wheelbase of large tractor:

$$
w b_{1}=\lambda \cdot w b_{0}
$$

Target tire diameter of a large tractor for the same surface pressure as for a small tractor:

$$
d_{1, \text { target,pressure }}=\sqrt{\lambda^{1,23}} \cdot \lambda \cdot d_{0}
$$

\section{Constant shear stresses in contact surface}

Analogous considerations have been made for the shear stresses $\tau$ in the contact surface. Again the tire-dimensions should be increased over proportionally, which is described by the factor $\gamma$ :

$$
\begin{gathered}
\tau_{0} \approx \frac{P_{0}}{A_{R, 0}} \\
\tau_{1} \approx \frac{P_{1}}{A_{R, 1}}=\frac{P_{0} \cdot \lambda^{3,44}}{A_{R, 0} \cdot(\lambda \cdot \gamma)^{2}}=\frac{P_{0}}{A_{R, 0}}
\end{gathered}
$$

The variable $\mathrm{P}$ refers to the (traction-)power of the tractor. Equal shear stress requires an enlargement factor of $\gamma=\sqrt{\lambda^{1,44}}$, additionally to the proportional scaling in dimensions.

Target tire diameter of large tractor for the same shear stresses as for small tractor:

$$
d_{1, \text { target,shear }}=\sqrt{\lambda^{1,44}} \cdot \lambda \cdot d_{0}
$$

\section{E. Analysis of Tire Dimensions}

Selected tractors have been scaled to a $100 \mathrm{~kW}$ reference model. As shown in figure 7 the tire dimensions already increase with increasing power (indicated in green color).

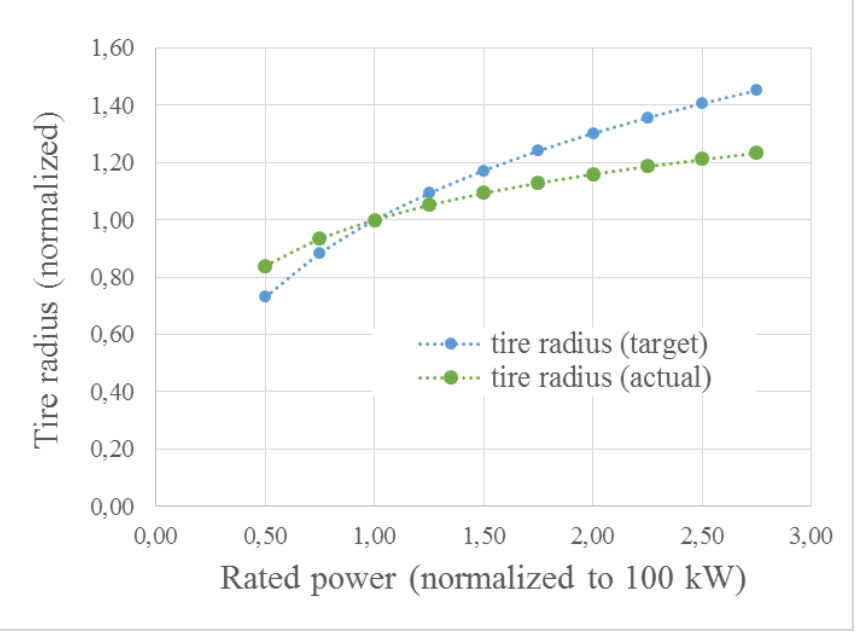

Figure 7. Rated power and tire-radius (target and actual) normalized to rated-power

But the increase is insufficient, neither for equal contact pressure nor for equal shear stresses. Interestingly enough, small tractors have relatively big wheels considering their weight. 


\section{CONCLUSION AND SUMMARY}

Based on the data of 117 analyzed tractors the displacement (digressively) increases with the engine power. Unloaded mass and engine power show a decent correlation. For every single $\mathrm{kW}$ of power the weight increases by $45 \mathrm{~kg}$, statistically. The wheelbase was assumed as a measure of tractor-dimension. The engine power increases by the $3.44^{\text {th }}$ degree, while the tractor mass increases with a degree of 3.23. As the tire diameter increases only linear with the wheelbase, higher pressure and higher shear stresses emerge at the contact surface. Therefore, bigger tires are recommended for large tractors - even as standard equipment.

\section{ACKNOWLEDGMENT}

The author thanks Mr. Gerald Rammel for his persistent investigation in tractor data, enabling further fundamental research in tractor engineering.

\section{REFERENCES}

[1] K. T. Renius, "Traktoren 2006," Landtechnik 61, No.4, pp. 186-187, 2006

[2] K. T. Renius, „Global transmission concepts for tractors,” ATZoffhighway 6 (2014), No. 2, pp.16-29

[3] G. Rammel, "Recherche, Zusammenfassung und statistische Auswertung von Traktorkennwerten," Diploma thesis HBLFA Francisco Josephinum, 2014

[4] J. Paar, „Steyr trotz Verluste Nummer 1,“ Der fortschrittliche Landwirt No.3/2014, pp.71-75

[5] H. Lampel, „Was sagen die Leistungsdaten eines Traktormotors aus?,“ Landwirtschaftliches Tagebuch 2007, HELGU-Verlag, Graz, pp. 58-65

[6] M. Landis, „Leistungsangaben in Prospekten,“ available online: http://www.landwirt.com/Leistungsangaben-in-Prospekten-Was-sagensie-aus, 7960,,Bericht.html; access at 24.04.2015

[7] H. Grohe, G. Russ, „Otto- und Dieselmotoren,“ Vogel Verlag, $14^{\text {th }}$ edition, Würzburg, 2007

[8] M. Rempfer, „Grundlagen der automatischen Reifenluftdruckverstellung bei Traktoren, "PhD-thesis TU-München, Fortschritt-Berichte VDI Reihe 14, No. 111., Düsseldorf: VDI-Verlag 2003

\section{AUTHOR PROFILE}

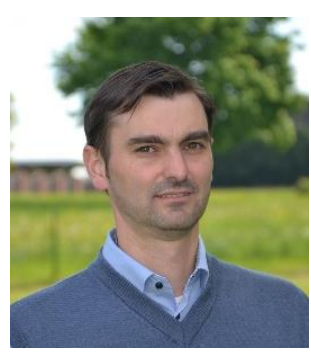

Jürgen Karner received an $\mathrm{MSc}$ and a $\mathrm{PhD}$ degree in Engineering Management from the University of Technology in Vienna, Austria.

$\mathrm{He}$ is Chief Scientific Officer (CSO) at Josephinum Research, Wieselburg, Austria. His research interests include tractors, hybrid-systems and implement technology. 